\title{
Estimation of Extracellular Volume in Preterm Infants $<1500$ g, Children, and Adults by Sucrose Dilution
}

\author{
K. BAUER, H. VERSMOLD, A. PRÖLSS, S. S. N. DE GRAAF, \\ W. P. MEEUWSEN-VAN DER ROEST, and W. G. ZIJLSTRA \\ Division of Neonatology, Department of Obstetrics and Gynecology, University of Munich, FRG [K.B., H.V., \\ A.P.]; and Division of Pediatric Oncology, Department of Pediatrics [S.S.N.d.G.], and Department of Physiology, \\ University of Groningen, The Netherlands [W.P.M-V.d.R., W.G.Z.]
}

\begin{abstract}
Extracellular volume can be estimated from the distribution volume of sucrose ( $V_{d}$ sucrose). The purpose of this study was to establish sucrose pharmacokinetics in preterm infants $<1500 \mathrm{~g}$ compared to children and adults and to define an optimal sampling scheme. In five preterm infants, 10 children, and five adults $V_{d}$ sucrose after a single injection was calculated with the two-compartment model ( $\mathrm{V}_{\mathrm{d}}$ sucrose-TCM) and with the one-compartment model applied only to the elimination phase of the same concentration-time curve $\left(V_{d}\right.$ sucrose-OCM $)$. In preterm infants $V_{d}$ sucrose-TCM was $417 \pm 45 \mathrm{~mL} / \mathrm{kg}$ $($ mean $\pm \mathrm{SD})$. $\mathrm{V}_{\mathrm{d}}$ sucrose-OCM was only $3.0 \pm 2.3 \%$ higher, because sucrose elimination half-life was on average 250 times longer than distribution half-life. Therefore $\mathbf{V}_{d}$ sucrose-OCM, requiring only four blood samples between 2 to $5 \mathrm{~h}$ after injection, gave an adequate estimate of $V_{d}$ sucrose in preterm infants $<1500 \mathrm{~g}$. $V_{d}$ sucrose-TCM in children and adults was $188 \pm 26$ and $189 \pm 17 \mathrm{~mL} / \mathrm{kg}$, respectively. $V_{d}$ sucrose-OCM was 10 to $65 \%$ higher. Therefore, in children and adults only $V_{d}$ sucrose-TCM gives a reliable estimate of $V_{d}$ sucrose. This requires 10 to 15 blood samples. The reduced sampling scheme was used in an extension of the study of preterm infants including five additional infants. $V_{d}$ sucrose-OCM in the preterm infants was $462 \pm 47 \mathrm{~mL} / \mathrm{kg}$ at birth and $425 \pm 46 \mathrm{~mL} / \mathrm{kg}$ at maximal postnatal wt loss. Postnatal wt loss (mean $\mathbf{- 8 3}$ $\pm 44 \mathrm{~g}$ ) was not significantly different from postnatal reduction of $V_{d}$ sucrose-OCM (mean $-82 \pm 56 \mathrm{~mL}$ ), suggesting that postnatal wt loss mainly represents extracellular fluid loss. (Pediatr Res 27: 256-259, 1990)
\end{abstract}

\section{Abbreviations}

$\mathrm{V}_{\mathrm{d}}$ sucrose-TCM, distribution volume of sucrose calculated from the two-compartment model

$V_{d}$ sucrose-OCM, distribution volume of sucrose calculated from the one-compartment model

The knowledge of changes in extracellular volume of preterm infants is important for the understanding of the nature of postnatal wt loss and rational planning of parenteral nutrition. Previous studies of extracellular volume in preterm infants may be subject to criticism. First, they date from times of high volume fluid therapy (1). Second, sodium bromide, which was the most

Received July 18, 1989; accepted October 24, 1989.

Correspondence and requests for reprints Karl Bauer, Department of Pediatrics, University of Munich, Lindwurmstr. 4, D-8000 München 2, FRG. frequently used indicator, is not confined to the extracellular space, but does enter cells (2). Sucrose is a more adequate indicator, because it does not enter cells. Sucrose has been used in adults as an indicator of extracellular volume (3-6). The first pediatric study using sucrose was done in small-for-gestationalage preterm infants (7). The authors assumed a mono-exponential concentration-time curve, but did not investigate sucrose pharmacokinetics in this particular patient population. Compared to children and adults, preterm infants have a large extracellular volume and a low glomerular filtration rate, which must affect sucrose disposition. The pharmacokinetics of sucrose in preterm infants have not been studied. To minimize the number of blood samples necessary, we evaluated the accuracy of calculating $\mathrm{V}_{\mathrm{d}}$ sucrose with the one-compartment model applied only to the elimination phase of the concentration-time curve $\left(\mathrm{V}_{\mathrm{d}} \mathrm{Suc}\right.$ rose-OCM).

\section{MATERIALS AND METHODS}

Subjects. Sucrose distribution and elimination were studied in 10 preterm infants, 10 children, and five adults. Informed consent was obtained from each patient and/or the parents. The study was approved by the hospital's ethical committee.

Preterm infants. Ten preterm infants were studied during the first days of life. Their gestational age was $28 \pm 1.7$ wk (mean \pm $\mathrm{SD})$ and their birth wt was $1.1 \pm 0.1 \mathrm{~kg}$ (appropriate for gestational age). Infants were included in the study if they had an umbilical artery catheter inserted on clinical grounds. At the time of the investigation all infants required artificial ventilation. Exclusion criteria were gross edema, renal failure, cardiac failure, hypotension, and diuretic therapy. Infants were covered with a plastic blanket and nursed in incubators at thermoneutral temperature. Fluid therapy was directed according to our nursery guidelines, allowing for a wt loss up to $10 \%$ of birth wt.

Each infant was studied within the first $12 \mathrm{~h}$ of life, and again when postnatal wt loss was approximately $10 \%$, which occurred at an age of $86 \pm 10 \mathrm{~h}$ (mean $\pm \mathrm{SD})$. The infants were given an injection of $2 \mathrm{~mL} / \mathrm{kg}$ of a solution of sucrose $(300 \mathrm{mmol} / \mathrm{L})$. The exact amount given was determined by weighing the syringe before and after the injection and measuring the concentration and density of the indicator solution. In all infants blood samples $(200 \mu \mathrm{L}$ each) were taken before and at $120,180,240$, and 300 min after injection (elimination phase). On five occasions we took additional early samples during the distribution phase at 2 , $5,10,30,60,90 \mathrm{~min}$ after injection.

Children and adults. The children were 6.1 (3.4-12.1) (median, range) y of age; their wt was $22.2(11.8-37.6) \mathrm{kg}$. The children were studied before the start of cytostatic therapy for various neoplasms. The adults were $21.5(17.1-42.8)$ y of age; their wt was $64.7(59.5-71.4) \mathrm{kg}$. One of them was a healthy volunteer, 
the others were studied before the start of cytostatic therapy for various neoplasms. Children and adults were given a single injection of $1 \mathrm{~mL} / \mathrm{kg}$ of sucrose $(300 \mathrm{mmol} / \mathrm{L})$. Blood samples (2 mL each) were taken prior to and at 5, 10, 15, 20, 25, 30, 40, $50,60,70,80,90,100,120,135$, and $150 \mathrm{~min}$ after injection.

Analytical Methods. Sucrose concentration was measured with the method described by Zweens and Frankena (6). After deproteinization of the plasma with trichloracetic acid $(0.6 \mathrm{~mol} / \mathrm{L})$ and destruction of reducing monosaccharides with potassium hydroxide $(5.4 \mathrm{~mol} / \mathrm{L}$ ), anthrone reagent (anthrone $10 \mathrm{mmol} / \mathrm{L}$ and thiourea $130 \mathrm{mmol} / \mathrm{L}$ in $\mathrm{H}_{2} \mathrm{SO}_{4} 15 \mathrm{~mol} / \mathrm{L}$ ) reacts with the fructose moiety of sucrose resulting in a greenish color. The absorbance was measured at $605 \mathrm{~nm}$ using a UV/VIS spectrophotometer 554 (Perkin Elmer Corporation, Norwalk, CT). The sample volume needed for one measurement of sucrose concentration in children and adults was $250-\mu \mathrm{L}$ plasma (6). For preterm infants we could reduce the sample size to $50-\mu \mathrm{L}$ plasma with an in vitro coefficient of variation of $0.8 \%(n=10)$. Each value was measured in duplicate. The measured concentrations were corrected to concentrations in plasma water knowing the plasma protein concentration (8).

Pharmacokinetic Analysis. Two different pharmacokinetic models were applied to the data, the two-compartment and the one-compartment model $(9,10)$. The two-compartment model makes the following assumptions: The distribution volume consists of a central compartment and a peripheral compartment. The drug is distributed instantaneously over the central compartment. It is further distributed to the peripheral compartment as long as there is a concentration gradient between the two compartments. The drug is eliminated only from the central compartment. Both distribution and elimination follow first order kinetics. The concentration-time curve consists of the distribution and the elimination phase and can be described by a bi-exponential function:

$$
c_{t}=A \cdot e^{-\alpha t}+B \cdot e^{-\beta t}
$$

where $c_{t}$ is the concentration at time $t, A$ and $B$ are the coefficients, $\alpha$ and $\beta$ the exponents of the two components of the concentration-time curve.

The parameters of the bi-exponential function were determined from the concentration-time curve by curve-fitting using a nonlinear least-squares computer program (ENZFITTER by R.J. Leatherbarrow, London). The distribution volume $\left(\mathrm{V}_{\mathrm{d}^{-}}\right.$ TCM) was calculated as follows:

$$
\mathrm{V}_{\mathrm{d}} \mathrm{TCM}=\mathrm{m}_{\mathrm{i}} \cdot \frac{\mathrm{A} / \alpha^{2}+\mathrm{B} / \beta^{2}}{(\mathrm{~A} / \alpha+\mathrm{B} / \beta)^{2}}
$$

where $m_{i}$ is the amount of indicator administered. The distribution half-life is $\ln 2 / \alpha$, the elimination half-life is $\ln 2 / \beta$.

The one-compartment model assumes instantaneous drug distribution over its final distribution volume. Data during the distribution phase are therefore disregarded and the elimination phase of the concentration-time curve is described by a monoexponential function:

$$
c_{t}=c_{0} \cdot e^{-k t}
$$

where, $c_{0}$ is the concentration at time 0 , and $\mathrm{k}$ the elimination rate constant. The distribution volume $\left(\mathrm{V}_{\mathrm{d}}-\mathrm{OCM}\right)$ is:

$$
\mathrm{V}_{\mathrm{d}}-\mathrm{OCM}=\frac{\mathrm{m}_{\mathrm{i}}}{\mathrm{c}_{0}}
$$

When the elimination takes very long compared to the distribution, $\mathrm{V}_{\mathrm{d}}$ sucrose-OCM gives an adequate estimate of the distribution volume. But when the elimination does not take much more time than the distribution, $\mathrm{V}_{\mathrm{d}}$ Sucrose-OCM overestimates the distribution volume $(11,12)$. We compared $\mathrm{V}_{\mathrm{d}}$-TCM and $\mathrm{V}_{\mathrm{d}}-\mathrm{OCM}$ to evaluate this overstimation:

$$
\text { overestimation }(\%)=\frac{V_{d}-O C M-V_{d}-T C M}{V_{d}-T C M} \cdot 100
$$

Statistics. Statistical analysis was performed by means of the Student's $t$ test and regression analysis. Results were considered statistically significant when $p<0.05$.

\section{RESULTS}

Sucrose pharmacokinetics in preterm infants. In five preterm infants the two-compartment model was used (Table 1). $\mathrm{V}_{\mathrm{d}}$ sucrose-TCM was $417 \pm 45 \mathrm{~mL} / \mathrm{kg}$ (mean $\pm \mathrm{SD}$ ). Elimination halflife was 250 times longer than distribution half-life, due to the very slow sucrose elimination (Fig. $1 a$ ). Therefore, $\mathrm{V}_{\mathrm{d}}$ sucroseOCM overestimated $\mathrm{V}_{\mathrm{d}}$ sucrose-TCM by $3.0 \pm 2.3 \%$ (Fig. 2 ). Overestimation increased with increasing sucrose elimination

Table 1. Pharmacokinetic parameters of sucrose after single injection calculated with two-compartment model

\begin{tabular}{lccc}
\hline & $\begin{array}{c}\text { Preterm } \\
\text { infants }\end{array}$ & Children & Adults \\
\hline Number of patients & 5 & 10 & 5 \\
$\mathrm{~V}_{\mathrm{d} \text { sucrose- } \mathrm{TCM}(\mathrm{mL} /}$ & $417 \pm 45^{*}$ & $188 \pm 26 \dagger$ & $189 \pm 17 \dagger$ \\
$\quad \mathrm{kg})$ & $2.3 \pm 1.3$ & $6.1 \pm 3.4$ & $10.0 \pm 5.3 \ddagger$ \\
$\begin{array}{c}\text { Distribution half-life } \\
\text { (min) }\end{array}$ & $582 \pm 199$ & $58 \pm 8 \dagger$ & $71 \pm 7 \dagger$ \\
$\begin{array}{c}\text { Elimination half-life } \\
\text { (min) }\end{array}$ & & & \\
\hline
\end{tabular}

$*$ Mean \pm SD.

$\dagger p<0.001$ versus preterm infants.

$\ddagger p<0.01$ versus preterm infants.

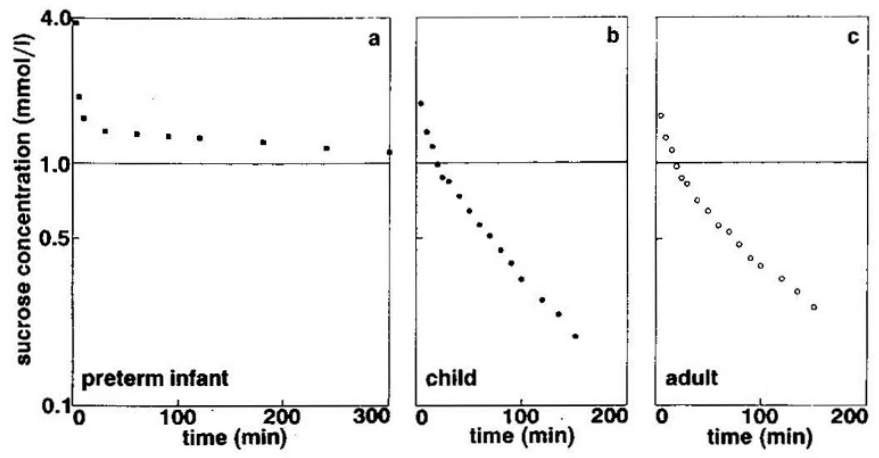

Fig. 1. Sucrose concentration-time curves following a single injection in $(a)$ a preterm infant, $(b)$ a child, and $(c)$ an adult.

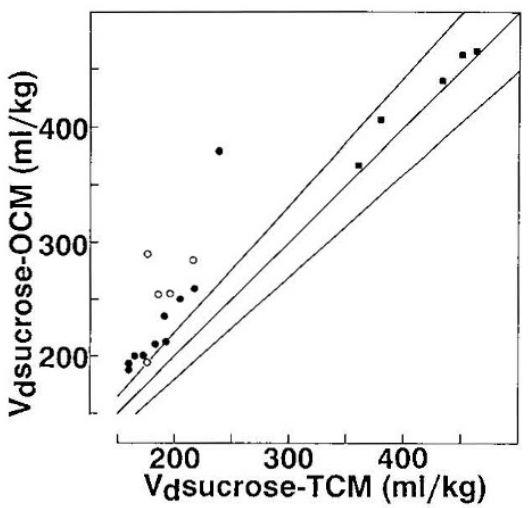

Fig. 2. Relationship between $V_{d}$ sucrose-TCM and $V_{d}$ sucrose-OCM in preterm infants $(\square)$, children $(\bullet)$, and adults $(O)$. Lines represent identity line and $\pm 10 \%$ range. 
rate constant $\beta\left(\mathrm{min}^{-1}\right)$, which describes the slope of the elimination phase. The regression equation was $(r=0.915, n=5, p$ $<0.01$ ):

$$
\text { overestimation }(\%)=4700 \cdot \beta-3.2
$$

Thus the elimination rate constant was used to predict the overestimation when no data from the distribution phase were available.

Sucrose pharmacokinetics in children and adults. In 10 children and five adults the two-compartment model was used (Table 1). Sucrose pharmacokinetics were very similar in children and adults. $\mathrm{V}_{\mathrm{d}}$ sucrose-TCM was $188 \pm 26 \mathrm{~mL} / \mathrm{kg}$ in children and $189 \pm 17 \mathrm{~mL} / \mathrm{kg}$ in adults. Elimination half-life was only six to nine times longer than distribution half-life (Fig. $1 b$ and $c$ ). Therefore $\mathrm{V}_{\mathrm{d}}$ sucrose-OCM overestimated $\mathrm{V}_{\mathrm{d}}$ sucrose-TCM by 23 $\pm 14 \%$ in children and by $35 \pm 19 \%$ in adults (Fig. 2 ).

Postnatal changes of $V_{d}$ sucrose-OCM and body wt in preterm infants. The postnatal changes of $\mathrm{V}_{\mathrm{d}}$ sucrose-OCM were estimated in 10 preterm infants using only four blood samples 120,180 , 240 , and $300 \mathrm{~min}$ after injection and the one-compartment model (Table 2). $V_{d}$ sucrose-OCM was $462 \pm 47 \mathrm{~mL} / \mathrm{kg}$ on $\mathrm{d} 1$ $($ age $5.8 \pm 3.6 \mathrm{~h})$ and $425 \pm 46 \mathrm{~mL} / \mathrm{kg}$ on $3($ age $86 \pm 10 \mathrm{~h})$. Postnatally, the elimination rate $\beta$ increased from $0.12 \cdot 10^{-2} \pm$ $0.05 \cdot 10^{-2} \mathrm{~min}^{-1}$ on $\mathrm{d} 1$ to $0.17 \cdot 10^{-2} \pm 0.06 \cdot 10^{-2} \mathrm{~min}^{-1}$ on $\mathrm{d} 3$. Consequently, the overestimation of the distribution volume calculated with the equation described above increased from 2.4 $\pm 2.2 \%$ on $\mathrm{d} 1$ to $4.9 \pm 2.9 \%$ on $\mathrm{d} 3$. Mean postnatal wt loss was $83 \pm 44 \mathrm{~g}$ and mean decrease in $\mathrm{V}_{\mathrm{d}}$ sucrose-OCM was $82 \pm 56$ $\mathrm{mL}$.

\section{DISCUSSION}

We estimated extracellular volume by sucrose dilution. We found that in preterm infants, due to the very slow sucrose elimination, $V_{d}$ sucrose can be reliably estimated from four blood samples, taken between 2 and $5 \mathrm{~h}$ after injection ( $\mathrm{V}_{\mathrm{d}}$ sucroseOCM). In children and adults, due to the faster sucrose elimination, $V_{d}$ sucrose can only be estimated with the two-compartment model, requiring at least ten blood samples between 2 and $150 \mathrm{~min}$ after injection $\left(\mathrm{V}_{\mathrm{d}} \mathrm{sucrose}-\mathrm{TCM}\right)$. In planning an appropriate sampling scheme for indicator dilution studies, it is not only important to know the different pharmacokinetics of the different indicators, as recently shown by Brans et al. (13), but also to know the different pharmacokinetics in different patient populations.

We chose sucrose, because it has the advantage to estimate the readily exchangeable extracellular volume (14), i.e. plasma, lymph, and interstitial fluid (8). Diffusion into the structurebound dense connective tissue water can be ignored when study times are short, and sucrose enters transcellular fluids (e.g. cerebrospinal fluid, ascites) only in traces (4). Sucrose does not enter cells. Intravenously administered sucrose is not metabolized, but completely eliminated via the kidneys. Mean urinary recovery of sucrose in adults ranges from $93 \%$ (7) to $99 \%$ (3). Sucrose clearance is of the same magnitude as creatinine clearance in adults (6), suggesting mere glomerular filtration of sucrose. Consequently, for studies of the short term changes of extracellular volume, sucrose should be more appropriate than sodium bromide (15). Sodium bromide, the extracellular volume indicator up to now most frequently used in preterm infants enters cells in about $10 \%$ of the dose given (2) and is selectively accumulated in red blood cells, stomach, and skin (16). A correction factor for intracellular bromide has been recommended ("corrected bromide space") (17), but has been incorrectly applied by several investigators $(18,19)$. The long half-life of bromide in newborns (17) may lead to accumulation with repeated injections. The distribution volume of inulin, a polysaccharide indicator of extracellular volume, is very similar to that of sucrose (14). Inulin diffusion is three to five times slower than sucrose diffusion, because inulin is a larger molecule. Therefore the use of sucrose should be preferred (14).
We gave sucrose as a single injection, because the single injection technique does not require timed urine collections, which are especially unreliable in preterm infants, because the study time is short $(3-5 \mathrm{~h})$, and because the amount of indicator given is small. The major criticism of the single injection technique is the lack of a "real steady state" (20). The constant infusion technique provides a real steady state and is generally regarded as the most accurate method for measuring distribution spaces (4), but it needs an exactly measured continuous infusion of a large amount of tracer over as long as $8-24 \mathrm{~h}$ and is dependent on timed urine collections, i.e. catheterization of the bladder. $\mathrm{V}_{\mathrm{d}} \mathrm{sucrose}$ in adults obtained by single injection technique was $218 \pm 25 \mathrm{~mL} / \mathrm{kg} \mathrm{(6)}$ and $194 \pm 49 \mathrm{~mL} / \mathrm{kg}$ (4) by continuous infusion. In preterm infants there are only data on inulin, an indicator behaving similarly to sucrose. Again, the distribution volume by single injection $(316 \pm 43 \mathrm{~mL} / \mathrm{kg})$ did not differ significantly from the distribution volume by constant infusion $(351 \pm 81 \mathrm{~mL} / \mathrm{kg})(21)$. In summary, the single injection technique gives similar results and is associated with much less procedural difficulties in preterm infants. Only techniques requiring small numbers of blood samples can be used in preterm infants. We therefore evaluated the use of $V_{d}$ sucrose-OCM in the three age groups (Fig. 2).

In preterm infants, the pharmacokinetic behavior of sucrose was characterized by a large distribution volume and a very slow elimination. Various other studies using different methods of extracellular volume estimation $(22,23)$ also found an extracellular volume of $40-50 \%$ of body wt in preterm infants. v. d. Wagen et al. (24), using sucrose in more mature small-forgestational-age infants (gestational age $>34 \mathrm{wk}$ ), found a smaller sucrose space (mean $355 \mathrm{~mL} / \mathrm{kg}$ ). This could be explained by the decrease of the extracellular volume with increasing gestational age (25). In the preterm infants of our study $\mathrm{V}_{\mathrm{d}}$ sucroseOCM overestimated $V_{d}$ sucrose-TCM by only $3.0 \pm 2.2 \%$. Coulthard (21) studying inulin clearance in preterm infants found an overstimation of inulin clearance by one-compartment analysis of $4.5 \%$. In preterm infants we felt justified to use $V_{d}$ sucroseOCM, because this form of analysis allowed a substantial reduction of blood samples and the overestimation thus introduced was small. These results justify after the event v. d. Wagen's ( 7 , 24) assumption of a monoexponential concentration-time curve, but are valid only as long as the GFR and sucrose elimination are low. With the increase of the GFR with gestational and postnatal age, the overestimation might reach unacceptable levels already in term neonates.

There were no significant differences of sucrose pharmacokinetics between children and adults. $\mathrm{V}_{\mathrm{d}}$ sucrose-OCM overestimated $\mathrm{V}_{\mathrm{d}}$ sucrose-TCM by $23 \pm 14 \%$ in children and by $39 \pm$ $15 \%$ in adults. In children and adults only $V_{d}$ sucrose-TCM can be used.

In 10 preterm infants we used $\mathrm{V}_{\mathrm{d}}$ sucrose-OCM to evaluate the postnatal changes of extracellular volume with postnatal wt loss (Table 2). The results validate, that $\mathrm{V}_{\mathrm{d}}$ sucrose-OCM can be used

Table 2. Postnatal changes in body wt, $V_{d}$ sucrose-OCM, and fractional elimination rate constant $\beta$-sucrose in 10 preterm

\begin{tabular}{lccc}
\multicolumn{4}{c}{ infants $<1500 \mathrm{~g}$} \\
& Day 1 & Day 3 & Difference \\
\hline Age $(\mathrm{h})$ & $5.8 \pm 3.6^{*}$ & $86 \pm 10$ & \\
$\mathrm{Wt}(\mathrm{g})$ & $1113 \pm 97$ & $1029 \pm 198 \dagger$ & $(-83)$ \\
$\mathrm{V}_{\mathrm{d}}$ sucrose-OCM $(\mathrm{mL})$ & $515 \pm 121$ & $433 \pm 127 \dagger$ & $(-82)$ \\
$\mathrm{V}_{\mathrm{d}}$ sucrose-OCM $(\mathrm{mL} / \mathrm{kg})$ & $462 \pm 47$ & $425 \pm 46 \ddagger$ & \\
$\beta$-sucrose $\left(10^{-2} \mathrm{~min}^{-1}\right)$ & $0.12 \pm 0.05$ & $0.17 \pm 0.06 \ddagger$ & \\
Fluid intake $\left(\mathrm{mL} \mathrm{kg}^{-1} \mathrm{~d}^{-1}\right)$ & $58 \pm 9$ & $127 \pm 25 \dagger$ & \\
Na $^{+}$intake $\left(\mathrm{mmol} \mathrm{kg}^{-1}\right.$ & 0 & $5.8 \pm 2.1 \dagger$ &
\end{tabular}
$\mathrm{d}^{-1}$ )

$*$ Mean \pm SD.

$\dagger p<0.001$ versus $\mathrm{d} 1$.

$\ddagger p<0.05$ versus $\mathrm{d} 1$. 
for a longitudinal study in preterm infants. The mean reduction of $\mathrm{V}_{\mathrm{d}}$ sucrose-OCM of $82 \mathrm{~mL}$ and the mean wt loss of $83 \mathrm{~g}$ did not differ significantly, suggesting that postnatal wt loss is fluid loss from the extracellular space. Shaffer et al. (26) found the same in preterm infants measuring bromide space. Postnatal increase in GFR was reflected in the concomitant increase in the fractional elimination rate constant of sucrose (Table 2). This led to an increase of the overestimation of the distribution volume from d 1 to 3 and introduced a relative error of $2.7 \pm$ $2.3 \%$, when comparing $\mathrm{V}_{\mathrm{d}}$ sucrose-OCM of $\mathrm{d} 1$ and 3 .

Up to now the ideal indicator of extracellular volume has not been found and several different indicators are still advocated. Each presents specific problems and the results must be interpreted with great care. We presented data on sucrose, an indicator especially useful to measure the functional, readily exchangeable extracellular volume. A substantial reduction of the number of blood samples was possible in preterm infants allowing long term studies of $\mathrm{V}_{\mathrm{d}}$ sucrose even in this delicate group of patients.

Acknowledgment. The authors thank Prof. A. Okken, Department of Pediatrics, University of Groningen, for helpful advice.

\section{REFERENCES}

1. Frijs-Hansen B 1971 Body composition during growth. Pediatrics 47:264-274

2. Cheek DB 1961 Extracellular volume: its structure and measurement and the influence of age and disease. J Pediatr 58:103-125

3. Keith NM, Power MH 1937 The urinary excretion of sucrose and its distribution in the blood after intravenous injection into normal men. Am J Physiol 120:203-210

4. Peterson RE, O'Toole JJ, Kirkendall W 1959 The variability of extracellular fluid space (sucrose) in man during a 24 hour period. J Clin Invest 38:16441656

5. Chesley LC 1979 Parenteral magnesium sulfate and the distribution, plasma levels, and excretion of magnesium. Am J Obstet Gynecol 133:1-7

6. Zweens J, Frankena H 1980 Sucrose as an indicator for the measurement of the extracellular fluid volume in man. Proceedings of the 21st Dutch Federation Meeting, Nijmegen, The Netherlands

7. vd Wagen A, Okken A, Zweens J, Zijlstra WG 1985 Composition of postnatal weight loss and subsequent weight gain in small for dates newborn infants. Acta Paediatr Scand 74:57-61
8. Forbes GB 1987 Techniques for estimating body composition. In: Forbes GB (ed) Human Body Composition. Springer, New York, pp 5-23

9. Greenblatt DJ, Koch-Weser J 1975 Clinical pharmacokinetics. N Engl J Med 293:702-705

10. Sapirstein LA, Vidt DG, Mandel MJ, Hanusek G 1955 Volumes of distribution and clearances of intravenously injected creatinine in the dog. Am J Physio $181: 330-336$

11. Dominguez R, Corcoran AC, Page JH 1947 Mannitol: kinetics of distribution, excretion, and utilization in human beings. J Lab Clin Invest 32:1192-1202

12. Riegelman S, Loo JCK, Rowland M 1968 Concept of a volume of distribution and possible errors in evaluation of this parameter. J Pharmacol Sci 57:128 133

13. Brans YW, Andrew DS, Dutton EB, Schwartz CA, Carey KD 1989 Dilution kinetics of chemicals used for estimation of water content of body compartments in perinatal medicine. Pediatr Res 25:377-382

14. Deane N, Schreiner GE, Robertson J 1951 The velocity of distribution of sucrose between plasma and interstital fluid, with reference to the use of sucrose for the measurement of extracellular fluid in man. J Clin Invest 30:1463-1468

15. Walser M, Seldin DW, Grollma 1953 An evaluation of radiosulfate for the determination of the volume of extracellular fluid in man and dogs. $\mathrm{J}$ Clin Invest 32:299-304

16. Pierson RN, Price DC, Wang J, Jain RK 1978 Extracellular water measurements: organ tracer kinetics of bromide and sucrose in rats and man. Am J Physiol 235:254-264

17. Fink CW, Cheek DB 1960 The corrected bromide space (extracellular volume) in the newborn. Pediatrics 26:397-401

18. Bell EF, Ziegler EE, Forbes GB 1984 Letter to the editor. Pediatr Res 18:392393

19. Brans YW, Cassady G, Cheek DB 1984 Response to letter to the editor. Pediatr Res 18:393

20. White HL, Rolf D 1958 Comparison of various procedures for determining sucrose and inulin space in the dog. J Clin Invest 37:8-19

21. Coulthard MG 1983 Comparison of methods of measuring renal function in preterm babies using inulin. J Pediatr 102:923-930

22. Shaffer SG, Bradt SK, Meade VM, Hall RT 1984 Extracellular fluid volume changes in very low birth weight infants during first 2 postnatal month. $J$ Pediatr 111:124-128

23. Iob V, Swanson WW 1934 Mineral growth of the human fetus. Am J Dis Child 47:302-306

24. vd Wagen A, Okken A, Zweens J, Zijlstra WG 1986 Body composition at birth of growth-retarded newborn infants demonstrating catch-up growth in the first year of life. Biol Neonate 49:121-125

25. Frijs-Hansen B 1983 Water distribution in the fetus and newborn infant. Acta Paediatr Scand [Suppl] 305:7-11

26. Shaffer SG, Bradt SK, Hall RT 1986 Postnatal changes in total body water and extracellular fluid volume in the preterm infants with respiratory distress syndrome. J Pediatr 109:509-514 